\title{
Wasp stings (Vespa affinis) induced acute kidney injury following rhabdomyolysis in a 25-year-old woman
}

\section{Parash Ullah', Alamgir Chowdhury'2, Ishrat Tahsin Isha', Sultan Mahmood', Fazle Rabbi Chowdhury'", Mohammad Zeesan-ul- Abir ${ }^{3}$, Aziz Al Manna ${ }^{3}$, Mohammad Ismail Patwary'}

'Department of Medicine, Sylhet M.A.G Osmani Medical College, Sylhet, Bangladesh

2Department of Nephrology, Sylhet M.A.G Osmani Medical College, Sylhet, Bangladesh

3Sylhet M.A.G Osmani Medical College, Sylhet, Bangladesh

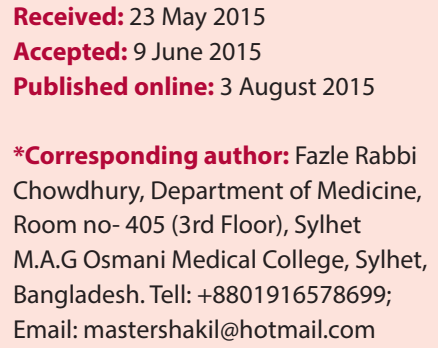

Received: 23 May 2015

Accepted: 9 June 2015

Published online: 3 August 2015

*Corresponding author: Fazle Rabbi Chowdhury, Department of Medicine, Room no- 405 (3rd Floor), Sylhet M.A.G Osmani Medical College, Sylhet, Bangladesh. Tell: +8801916578699 ;

Email: mastershakil@hotmail.com

Competing interests: None

\begin{abstract}
Wasp sting is a relatively common arthropod assault. This usually results in pain and mild allergic reactions, but sometimes may cause severe systemic reaction and multiorgan dysfunction including rhabdomyolysis, hemolysis, coagulopathy, hepatic, renal and cardiac complications. Along with several other pathomechanisms, rhabdomyolysis is a distinguished cause of acute kidney injury (AKI) in patients with wasp sting. We herein report a case in which the patient developed rhabdomyolysis followed by AKI due to multiple wasp stings. The offending wasp was brought to the hospital and the species was confirmed by a zoologist (Vespa affinis).

Keywords: Acute kidney injury, Rhabdomyolysis, Wasp venom

Citation: Ullah P, Chowdhury A, Isha IT, Mahmood S, Chowdhury FR, Zeesan-ul-Abir M, et al. Wasp stings (Vespa affinis) induced acute kidney injury following rhabdomyolysis in a 25-year-old woman. Journal of Emergency Practice and Trauma 2016; 2(2): 55-57. doi: $10.15171 /$ jept.2016.08
\end{abstract}

\section{Introduction}

Wasp sting may result in a wide range of clinical presentation ranging from localized pain and tissue necrosis to severe anaphylactic reaction. It can cause rhabdomyolysis, hemolysis, disseminated intravascular coagulation (DIC), acute tubular necrosis (ATN), acute kidney injury (AKI), centrilobular necrosis of liver, subendocardial necrosis, intracerebral hemorrhage, etc (1-3). AKI after wasp sting involves several pathomechanisms; among them rhabdomyolysis is a rare entity. In this case, a woman who was stung by a swarm of wasps in different sites of her body developed AKI due to rhabdomyolysis and needed intensive hemodialysis support for recovery.

\section{Case Report}

A 25-year-old woman was stung by a swarm of wasps at different sites of her body including face, head, chest, and back while walking down a street. Immediately she developed severe body ache and tenderness at the bite sites. She was taken to a primary health care center within an hour and was treated with injectable dexamethasone and chlorpheniramine. She was discharged after a couple of hours of observation. But few hours after discharge, she noticed the swelling of her face and arms, which gradually increased and involved both legs. She was then referred to a tertiary institute for better management. The lag period between wasp sting and hospitalization was approxi- mately 18 hours. She had no history of allergy or previous wasp sting.

On admission, she was anuric for 8 hours associated with nausea and vomiting. She was conscious but irritable, with her blood pressure at $100 / 60 \mathrm{~mm} \mathrm{Hg}$, pulse $68 / \mathrm{min}$, and respiratory rate $16 / \mathrm{min}$. There were approximately 180 200 bite marks (Figure 1) on her body. Stung areas were red, swollen and severely tender. Systemic examination was unremarkable apart from anasarca. Investigations revealed neutrophilic leukocytosis with hemoglobin $66 \%$, serum creatinine $3.2 \mathrm{mg} / \mathrm{dl}$, serum sodium $122 \mathrm{mmol} / \mathrm{l}$, and creatinine phosphokinase (CPK) $800 \mathrm{U} / \mathrm{L}$ (normal 30-135). Ultrasonogram of abdomen showed bilateral renal parenchymal injury. Her electrocardiogram (ECG) showed sinus tachycardia with $\mathrm{T}$ inversion in V1-V3 but troponin I was normal (1.1 IU). She remained anuric and had progressively worsening renal failure despite adequate hydration. Her urine output was $50 \mathrm{ml}$ on the third day after forced diuresis. Successively creatinine peaked to 7.12 $\mathrm{mg} / \mathrm{dl}$ and dialysis was initiated. Even after regular dialysis, creatinine reached $8.17 \mathrm{mg} / \mathrm{dl}$ on day 15 , and her urine output steadily increased to $500 \mathrm{ml}$ (Figure 2). From day 15 onwards, creatinine started to drop and became nor$\mathrm{mal}(1.5 \mathrm{mg} / \mathrm{dl})$ on day 28 . By that time, the total 20 -cycle dialysis was given. Other supportive measures included diuretics, hydrocortisone, antihistamine, and antibiotics. On the basis of history, offender species identification 

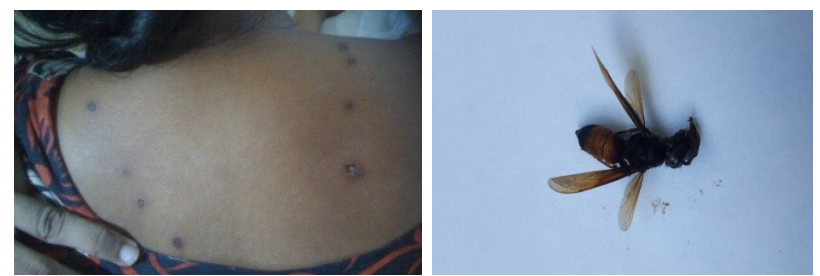

Figure 1. Multiple sting marks with central white necrosis and surrounded erythema and the offender species (Vespa affinis).

(Figure 1), clinical examination, and investigation reports, she was diagnosed as a case of AKI following rhabdomyolysis due to wasp envenomation (Vespa affinis). At discharge, her creatinine was $0.6 \mathrm{mg} / \mathrm{dl}$ and urinary output $2 \mathrm{~L} /$ day. All other laboratory investigations were normal.

\section{Discussion}

Wasp is one of the most common medically important hymenoptera in Bangladesh but wasp sting reporting is seldom done. Wasps usually deliver their toxin by stinging their victims when they become disturbed while searching for food, accidentally stepped on or swatted $(4,5)$. Sometimes wasp stings are wrongly called bee stings. The body shape of wasps is smooth and they sting repeatedly and occurrences happen near their nest or near soft drinks and cans, while the body shape of bees is fuzzy and they sting only once near their hive or flowers (6). Mass envenomation may occur when these insects respond to others as a threat to their colony. A gang of insects may be involved in stinging, which happened in this case. A sample of the offending insect was collected (Figure 1) and it was identified as Vespa affinis by an expert zoologist. The species matched with a previous report done by Chowdhury et al (7) from Bangladesh.

Wasp sting may cause anaphylactic shock which can occur in a previously sensitized person, following even a single sting. Previously unexposed people may develop multiple organ dysfunctions due to severe systemic envenomation. A number of about 500 stings have been considered necessary to cause death by direct toxicity, but as few as 3050 stings have been proved fatal in children (8). In this case around 180-200 sting marks were found all over the body. Our patient presented with anuria, raised creatinine level and high CPK, which proved rhabdomyolysis as the cause of her AKI. In rhabdomyolysis, striated muscles are injured and cause severe body ache and muscle ache. Our patient developed severe body ache on the day of incidence and we got high CPK on day 3. In the successive days, her creatinine kept rising for which she needed intensive haemodialysis. Even regular dialysis failed to normalize creatinine for some days, probably because of the delayed release of toxins and low renal clearance.

Wasp venom contains various biogenic substances that include polypeptides like apamin, enzymes (phospholipase $\mathrm{A}_{2}$ and hyaluronidase), and low molecular weight agents like histamine and amino acids (6). Phospholipase is the most important component causing rhabdomyolysis and

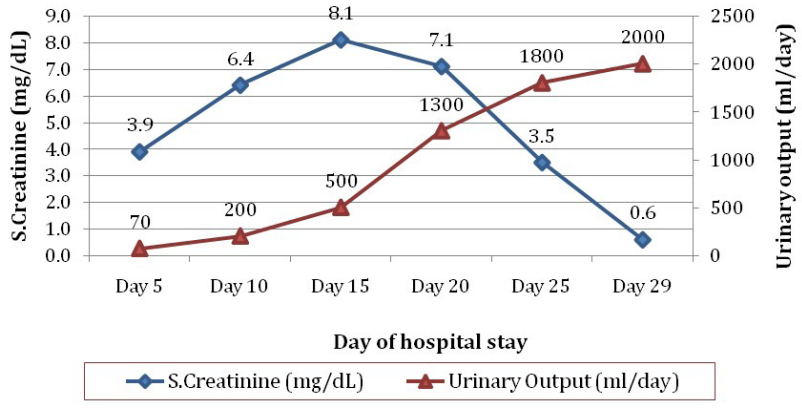

Figure 2. Day wise relation of urinary output and renal function

can also cause hemolysis $(6,8)$. Rhabdomyolysis can induce AKI by different mechanisms. Myoglobin released from striated muscle cause AKI by direct toxic effects on tubular epithelial cells, by inducing intralobular cast formation, or by producing pigment nephropathy. Myoglobin is also a potent inhibitor of nitric oxide and may cause intrarenal vasoconstriction and ischaemia in patients with renal hypo-perfusion. Another cause of renal insufficiency is acute interstitial nephritis which is thought to occur by direct effect of toxin $(9,10)$.

Clinical outcome depends upon duration to reach the hospital following the sting and initiation of aggressive management protocol (5). Possibly this patient might not have developed such critical condition if she had reached this hospital immediately and aggressive management was initiated earlier. In multiple wasp sting cases, we should consider not only anaphylaxis, but also the severe systemic reactions. However species specific report is important to understand the geographical distribution (North-east of Bangladesh) of wasp around the region and for better management of the cases. The issue should be addressed in the national guideline of poisoning management of Bangladesh, so that all level of physicians can respond promptly and effectively.

\section{Acknowledgments}

We cordially acknowledge the contribution of Mrs. Sonia Chowdhury, zoologist of Eden University College, Dhaka for her opinion regarding offender species identification.

\section{Ethical issues}

Written informed consent was obtained from the patient for publishing this case and any accompanying images.

\section{Authors' contributions}

MIP, AC and FRC diagnosed the case and supervised the management and follow up of the patient. PU, ISI, AAM and MZA were actively involved in managing the patient. PU and FRC wrote the case report. SM also contributed to the writing of the case report. All authors read and approved the final manuscript.

\section{References}

1. Thiruventhiran T, Goh BL, Leong CL, Cheah PL, Looi 
LM, Tan SY. Acute renal failure following multiple wasp stings. Nephrol Dial Transplant 1999; 14(1): 214 -7.

2. Kim YO, Yoon SA, Kim KJ, Lee BO, Kim BS, Chang YS, et al. Severe rhabdomyolysis and acute renal failure due to multiple wasp stings. Nephrol Dial Transplant 2003; 18(6): 1235.

3. Bhatta N, Singh R, Sharma S, Sinnha A, Raja S. Acute renal failure following multiple wasp stings. Pediatr Nephrol 2005; 20(12): 1809-10.

4. DiazJH. Hymenopterid bites, stings, allergic reactions, and the impact of hurricanes on hymenopteridinflicted injuries. J La State Med Soc 2007; 159 (3): 149-57.

5. Paudel B, Paudel K. A study of wasp bites in a tertiary hospital of western Nepal. Nepal Med Coll J 2009; 11(1): 52-6.

6. Zhang L, Young Y, Tang Y, Zhao Y, Cao Y, Su B, et al. Recovery from AKI following multiple wasp sting: a case series. Clin J Am Soc Nephrol 2013; 8(11): 1850-6.

7. Chowdhury FR, Bari MS, Shafi AM, Ruhan AM, Hossain ME, Chowdhury S, et al. Acute kidney injury following Rhabdomyolysis due to multiple wasp stings (Vespa affinis). Asia Pac J Med Toxicol 2014; 3: 41-3.

8. Bresolin NL, Carvalho LC, Goes EC, Fernandes R, Barotto AM. Acute renal failure following massive attack by Africanized bee stings. Pediatr Nephrol 2002; 17(8): 625-27.

9. Islam F, Taimur SD, Kabir CM. Bee envenomation induced acute renal failure in an 8 years old child. Ibrahim Med Coll J 2011; 5(1): 34-6.

10. Gunasekera WT, Mudduwa L, Lekamwasam S. Acute pigmented tubulopathy and interstitial nephritis following wasp sting. Galle Med J 2008; 13(1):55-6. 